\title{
ECOLODGE SEBAGAI SARANA AKOMODASI PARIWISATA BERKELANJUTAN
}

\author{
Rahma Aprilia Kumajii ${ }^{1,}$ Luchman Hakim $^{2}$, Edriana Pangestuti ${ }^{3}$ \\ Fakultas Ilmu Administrasi, Universitas Brawijaya, Malang, Indonesia \\ Email: rahmakumaji@student.ub.ac.id ${ }^{1}$, luchman@ub.ac.id²,edriana_fia@ub.ac.id ${ }^{3}$
}

\begin{abstract}
Ecotourism needs accommodation that simple, comfortable, provides unique nature experience, and of course ecologically acceptable. Ecolodges is one of the options for tourist who wants their accomodation to be environmentally friendly. That is why, ecolodge needs to be managed with sustainability principles. This literature review uses a systematic literature review approach. Empirical articles on the topic of ecolodge published between 2009 and 2019 were obtained from three reputable journal portals, totaling 56 articles. The articles are reduced to nine articles which are empirical articles, in English, and having ecolodge as the object of their research. The purpose of this literature review is to see the results of Ecolodge related research that has been conducted. This paper finds that several studies highlight the importance of standardization, solid governance, and partnership for ecolodge development. Other researches addresses the importance of local communities' perception and their capacity building development. Some studies also specifically address ecolodge as a form of indigenous tourism. Findings from several studies also indicate the importance of consumer satisfaction for effectiveness and efficiency in ecolodge management. This paper suggests that in future research directions should be conducted with more involvement from other stakeholders to evaluate ecolodge performance in various aspects.
\end{abstract}

Keywords: Ecolodge, Ecotourism, Sustainable Tourism

\begin{abstract}
ABSTRAK
Ekowisata membutuhkan akomodasi yang dapat diterima secara ekologis, sederhana, nyaman, dan memberikan pengalaman yang unik di lingkungan alam. Ecolodge sebagai akomodasi ekowisata menawarkan aspek-aspek tersebut dalam memfasilitasi wisatawan. Oleh karena itu ecolodge perlu dikelola dengan prinsip keberlanjutan. Tulisan ini merupakan literature review yang menggunakan pendekatan systematic literature review. Artikel empiris yang mengangkat topik ecolodge yang dipublikasikan antara 2009 dan 2019 diperoleh dari tiga portal jurnal bereputasi sebanyak 56 artikel. Artikel dikerucutkan menjadi sembilan artikel yang merupakan artikel empiris, berbahasa Inggris, dan menjadikan ecolodge sebagai objek penelitiannya. Tujuan dari literature review ini adalah untuk mengetahui hasil penelitian terkait ecolodge yang sudah pernah dilaksanakan. Tulisan ini menemukan bahwa beberapa penelitian ecolodge menyoroti pentingnya standardisasi, tata kelola yang solid, dan cooperative branding dalam pengembangan ecolodge. Penelitian lainnya membahas perlunya memperhatikan persepsi penduduk lokal di sekitar ecolodge dan bagaimana pengembangan kapasitas pada komunitas lokal. Beberapa penelitian juga secara spesifik membahas ecolodge sebagai salah satu bentuk indigenous tourism. Temuan dari beberapa penelitian juga menunjukkan pentingnya memperhatikan kepuasan konsumen ecolodge untuk efektivitas dan efisiensi pengelolaan. Rekomendasi untuk arah penelitian di masa depan adalah untuk mengadakan penelitian yang lebih melibatkan pengelola, penduduk lokal, dan konsumen dalam mengevaluasi performa ecolodge di berbagai aspek.
\end{abstract}

Kata Kunci: Ecolodge, Ekowisata, Pariwisata berkelanjutan 


\section{PENDAHULUAN}

Pariwisata berkelanjutan saat ini tengah dipromosikan pengembangannya untuk meminimalisir dampak lingkungan serta memaksimalkan manfaat sosial-ekonomi dalam sebuah destinasi wisata. World Tourism Organization mengembangkan konsep pariwisata berkelanjutan dan mendefinisikan aktivitas wisata dengan mengarahkan manajemen seluruh sumber daya dengan cara tertentu agar kebutuhan ekonomi, sosial, dan estetika dapat terpenuhi sambil menjaga integritas budaya, proses ekologi, keberagaman biologi, dan sistem pendukung kehidupan. Salah satu langkah dalam mewujudkan hal tersebut adalah dengan pengembangan ekowisata. Ekowisata sama halnya dengan pariwisata pada umumnya, harus memiliki fasilitas-fasilitas untuk mendukung produk wisatanya seperti atraksi, transportasi, dan akomodasi. Sarana akomodasi memiliki beberapa jenis dan karakteristik yang berbeda, sesuai dengan tujuan dan fasilitas yang diberikan. Penyesuaian tersebut bergantung pula pada tren kepariwisataan yang ada, saat ini pilihan wisatawan terhadap konsep berkelanjutan menjadi salah satu faktor dalam menentukan destinasi wisata, sarana akomodasi yang akan digunakan dan perencanaan perjalanan (Sirakaya-Turk et al., 2014).

Pergeseran tren pariwisata mendorong terjadinya pergeseran pada pemilihan fasilitas akomodasi. Akomodasi khusus kini bukan hanya mengedepankan aspek keuntungan ekonomi dan kepuasan wisatawan, namun sesuai dengan konsep pengembangan pariwisata berkelanjutan yang mempertimbangkan aspek kelestarian lingkungan fisik maupun sosial budaya, salah satu bentuknya adalah ecolodge. Terminologi "ecolodge" diluncurkan secara formal pada First International Ecolodge Forum and Field Seminar yang diadakan pada 1994 di Maho Bay Camps di Virgin Islands, Amerika Serikat. Ecolodge adalah fasilitas akomoasi, dengan 575 kamar, yang memiliki dampak kecil pada alam, finansialnya berkelanjutan, dan membantu melindungi kawasan sekitar yang sensitif, melibatkan dan menguntungkan bagi komunitas lokal, menawarkan pengalaman interpretatif dan interaktif, memberikan rasa kebersamaan dengan alam dan budaya, direncanakan, didesain, dibangun, dan bertindak dengan cara yang dapat diterima secara ekologi dan sosial (Blangy \& Mehta,
2006). Istilah ecolodge mulai banyak digunakan seiring tingginya kepedulian dan aksi masyarakat yang peduli dengan kelestarian lingkungan. Istilah ini membedakan ecolodge dengan sarana akomodasi lain, baik dari sisi proses pembangunannya hingga kegiatan operasionalnya. Oleh karena itu seiring maraknya pengembangan pariwisata berkelanjutan, penelitian-penelitian yang mengangkat topik ecolodge juga semakin berkembang.

Aspek fundamental untuk ecolodge selain perlindungan kawasan alam adalah pelatihan dan pendidikan. Terkait perlindungan lingkungan, mendirikan ecolodge selain harus berdampak mendekati nol pada alam, namun juga harus memiliki tujuan melindungi biodiversitas. Pelatihan dan pendidikan yang dimaksud adalah untuk warga lokal dan wisatawan. Pelatihan dilakukan untuk menambah pengetahuan dan pengalaman seputar ecolodge. Wisatawan juga mendapat kesempatan untuk belajar dari masyarakat lokal tentang lingkungan dan budaya sekitar. Apabila hal-hal tersebut dipahami dan diimplementasikan dengan benar, maka ecolodge dapat dikatakan sukses dan berkelanjutan, kemudian destinasi wisata di sekitar ecolodge dapat mengikuti prinsip yang sama dengan menciptakan jaringan kooperatif yang sehat dan adil, suatu daerah dapat mencapai pengembangan berkelanjutan (Kiper, 2013).

Tulisan ini merupakan literature review dari penelitian empiris bertopik ecolodge. Tujuan dari literature review ini adalah untuk mengetahui hasil penelitian yang berhubungan dan yang sudah pernah dilaksanakan (related research) dengan mengangkat topik ecolodge. Literature review ini akan menyoroti temuan dari penelitian-penelitian bertopik ecolodge yang berlangsung pada rentang waktu tahun 2009 hingga 2019. Bahasan pada tulisan ini terbagi ke dalam beberapa subtopik yaitu: Ecolodge: management, governance, and cooperative branding; Ecolodge in locals perspective: ethical issue and capacity building; Ecolodge and indigenous tourism; dan Ecolodge experiences reported online. Pembagian subtopik ini didasarkan tinjauan penulis bahwa penelitian bertopik ecolodge tidak mengerucut pada suatu pembahasan dan pendekatan tertentu dalam rentang waktu tersebut. Pembagian subtopik dilakukan untuk 
memperjelas paparan temuan dari penelitianpenelitian tersebut.

\section{KAJIAN PUSTAKA \\ Karakteristik Pengelolaan Ecolodge}

Ecolodge adalah fasilitas akomodasi pariwisata yang memenuhi kriteria di antaranya adalah: Melindungi lingkungan sekitar, baik alam dan budayanya; memiliki dampak minimal pada alam di sekelilingnya selama pembangunannya; sesuai dengan konteks fisik dan budaya melalui perhatian pada bentuk, lansekap dan warna, serta penggunaan arsitektur lokal; menggunakan sarana yang berkelanjutan untuk perolehan air dan mengurangi konsumsi air; menangani dengan hati-hati pembuangan limbah padat dan limbah lainnya; mendapatkan kebutuhan energinya dengan desain pasif dan mengkombinasikannya dengan rekan-rekannya untuk keberlanjutan yang lebih besar; mengupayakan untuk bekerja bersama dengan komunitas lokal; menawarkan program interpretatif untuk mendidik, baik pegawai dan wisatawan, seputar lingkungan alam dan budaya sekeliling; berkontribusi pada pengembangan lokal berkelanjutan melalui program penelitian (Blangy \& Mehta, 2006).

Ecolodge adalah sebuah hotel kecil atau guesthouse yang menggabungkan arsitektur lokal, budaya dan karakteristik alam, mendukung konservasi lingkungan dengan mengurangi limbah dan penggunaan energi serta memberikan manfaat sosial dan ekonomi bagi komunitas lokal (Elrouby, 2016). Manajemen dan operasi dari ecolodge berbeda dengan hotel pada umumnya karena berbagai alasan. Berdasarkan International Ecolodge Guidelines (Mehta, 2002), ecolodge seringkali ditemukan di area hutan belantara yang kurang berkembang, di daerah paling terpencil di negara manapun, oleh sebab itu, area tersebut merupakan tempat terakhir yang menerima investasi pemerintah dalam bidang kesehatan, pendidikan, listrik, air minum, jalan, dan lainlain. Hal ini menjadi tantangan khusus bagi pemilik atau manajer ecolodge yang harus mencapai pengembangan berkelanjutan dengan mendukung komunitas lokal pada program pengembangan jangka panjang dan menempatkan program konservasi di tempat yang mendapat bantuan minim dari luar. Pendidikan adalah salah satu medium utama yang akan menciptakan ekowisata yang sukses, dan hal ini sangat tergantung dari pemilik atau manajer ekowisata untuk menyediakannya.
Ecolodge memiliki beberapa karakteristik dalam manajemennya, yaitu: menyediakan on-the-job training pada anggota komunitas dan pemandu lokal; mempekerjakan staf yang mayoritas berasal dari masyarakat lokal, dan menghindari memberi tanggung jawab kunci pada orang-orang yang terlatih dari kota atau ekspatriat; mengadakan program bahasa kedua setelah jam kerja (untuk membantu staf dalam berbicara dengan bahasa tamu yang berkunjung) menggunakan masyarakat lokal yang sarjana dengan keahlian dalam pelatihan bahasa; membuat tamu berkontribusi pada pendidikan staf dan proyek pengembangan komunitas yang meliputi pendidikan atau kesehatan; mendorong anggota komunitas yang tertarik untuk mengkomunikasikan pengetahuan mereka tentang area sekitar, sembari menyemangati pemandu lokal untuk berbaur dengan tamu selama jam komunal; mendukung pengalaman belajar tamu melalui kunjungan pada peternakan lokal, pembibitan, proyek reboisasi, peternakan kupu-kupu dan upaya-upaya lainnya untuk mempromosikan keberlanjutan di sebuah daerah; mempromosikan sebuah sistem untuk tamu agar dapat berkontribusi secara finansial untuk pelestarian area alami di daerah tersebut; bersikeras untuk mendaur ulang apapun, dari meja hingga plastik, kertas, dan besi; menggunakan energi alternatif dimanapun yang memungkinkan; menggunakan deterjen yang biodegradable dan menghindari penggunaan racun kapanpun yang memungkinkan; dan yang terakhir adalah tidak mengurung hewan-hewan eksotik di daerah tersebut (Wood, 2015)

Pengembangan ecolodge baik pada tahap konstruksi, pengelolaan dan manajemen harus melibatkan komunitas lokal. Osland \& Mackoy (2004) menyebutkan beberapa karakteristik yang membedakan ecolodge dengan akomodasi tradisional lainnya, yaitu perbedaan ecolodge terletak pada desain yang terintegrasi dengan lingkungan alam, menyajikan makanan yang enak dan sehat, serta menyediakan aktivitas yang berbasis pendidikan alam. Bohdanowicz, (2005) menyebutkan jejak lingkungan dari hotel-hotel lebih besar dibanding fasilitasfasilitas lainnya yang berukuran sama, dikarenakan penggunaan sumber daya seperti air dan energi yang berlebihan. Oleh karena itu praktisi dan peneliti percaya bahwa era berikutnya untuk fasilitas akomodasi adalah era green hotel dan ecolodge, dengan fokus pada 
konservasi sumber daya lingkungan sebagai tujuan utama.

Ecolodge memiliki tiga efek, yaitu berdampak pada desain dan praktiknya berdampak pada lingkungan sekitar, pekerjaan dan pola pembelanjaannya mempengaruhi komunitas lokal, serta peningkatan kesadaran terhadap isu lingkungan berdampak pada ecotourist (Osland \& Mackoy, 2004). Terdapat beberapa faktor kunci penentu kesuksesan sebuah ecolodge. Pertama, destinasi lokasi ecolodge didirikan. Lokasinya harus menarik dan fokus pada ekologi dan margasatwa, dengan dukungan kebijakan pemerintah yang baik serta turut menangani sebagian biaya pelestarian lingkungan. Jangkauan media juga memainkan peranan penting dalam pemasaran ecolodge dan keterlibatan pemerintah. Kedua, ecolodge harus berbeda dengan kompetitornya dan menawarkan nilai terbaik dari harganya. Ketiga, ecolodge harus meningkatkan kesadaran tentang margasatwa dan alam dengan pemandu profesional dan pegawai yang sadar lingkungan. Keempat, ecolodge yang mudah dijangkau akan meningkatkan peluang mempromosikannya. Kelima, lokasi ecolodge dari atraksi lainnya. Keenam, pegawai yang terkualifikasi. Ketujuh, kreativitas, profesionalitas, dan kemampuan untuk memasarkan ecolodge dengan dana yang minim.

\section{Ecolodge: Management, Governance, And Cooperative Branding}

Ekowisata sebagai salah satu bentuk pariwisata, secara spesifik mengajak individu atau grup partisipan mencoba mengurangi efek yang biasanya dihasilkan oleh pariwisata konvensional. Pengembangan destinasi ekowisata memerlukan prasyarat dasar, salah satunya adalah fasilitas untuk akomodasi. Fasilitas ekowisata harus mempengaruhi lingkungan seminim mungkin, harus menyesuaikan diri dengan lingkungan, saat didirikan konstruksinya perlu disesuaikan dengan arsitektur tradisional dan material yang ada di sekitar, serta menggunakan sumber energi alternatif (Bulatović, 2017). Ecolodge adalah istilah yang digunakan untuk menunjukkan akomodasi wisata yang bergantung pada lingkungan dan sesuai dengan filosofi dan prinsip ekowisata (Hawkins et al., 1998). Hal ini mengacu pada fasilitas yang dibangun dan dikelola dengan prinsip ramah lingkungan. Beberapa isu terkait ecolodge adalah seputar alam dan atraksi budaya, cara mengelola fasilitas, pemasaran, dan keterlibatan komunitas lokal dalam proses pengembangan ecolodge.

Penelitian yang membahas pengelolaan ecolodge dan kesesuaiannya dengan prinsipprinsip manajemen ecolodge merupakan salah satu aliran yang muncul dalam literatur beberapa tahun terakhir. Salah satunya adalah penelitian Keough (2010). Penelitian dilakukan di Wenhai Ecolodge dengan melakukan observasi dan mengaitkannya dengan The International Ecolodge Guidelines (Keough, 2010). Terdapat sepuluh kriteria menurut The International Ecolodge Guidelines (Blangy \& Mehta, 2006) dan lima kriteria harus dipenuhi untuk sebuah akomodasi dianggap sebagai ecolodge, antara lain: (1) Membantu konservasi flora dan fauna di sekelilingnya; (2) Berusaha untuk bekerja bersama dengan komunitas lokal; (3) Menawarkan program interpretatif untuk mengedukasi pegawai dan wisatawan tentang alam di sekelilingnya serta lingkungan budayanya; (4) Menggunakan sarana alternatif dan berkelanjutan untuk memperoleh air dan mengurangi konsumsi air; (5) Menangani dan menyediakan tempat pembuangan yang tepat untuk limbah; (6) Menggunakan sumber energi yang dapat diperbarui dan berdesain pasif untuk kebutuhan energinya; (7) Menggunakan material dan teknologi tradisional untuk mendirikan bangunan dan dikombinasikan dengan teknologi modern untuk keberlanjutan yang lebih baik; (8) Memiliki dampak minimal pada alam di sekelilingnya selama pembangunan; (9) Menyesuaikan kondisi fisik yang spesifik dan konteks budaya dengan memperhatikan bentuk, lansekap dan warna dalam penggunaan arsitektur vernakular; (10) Berkontribusi untuk pengembangan komunitas lokal yang berkelanjutan melalui program edukasi dan penelitian.

Pengelolaan ecolodge juga dapat diteliti dengan menaruh fokus pada upaya-upaya kerjasama yang dilakukan ecolodge untuk meningkatkan kontribusinya dalam pariwisata berkelanjutan. Ekowisata adalah salah satu alat yang efektif untuk pengembangan berkelanjutan (Kiper, 2013). Menginap di ecolodge merupakan salah satu cara berpartisipasi di ekowisata. Prinsip ekowisata juga meliputi peningkatan kesadaran budaya dan sensitivitas, serta menguntungkan secara finansial dan memberdayakan masyarakat lokal dan konservasi (D. Fennell \& Dowling, 2003). 
Penelitian yang dilakukan oleh Buckley (2010) menunjukkan terjadinya pengembangan ecolodge sebagai bagian dari wisata konservasi yang diwujudkan dengan kerjasama antara komunitas lokal dan pengusaha swasta. Temuan penelitian ini sesuai dengan konsep Privatecommunity partnerships (PCP). Privatecommnunity partnerships (PCP) adalah satu dari banyak inisatif yang bertujuan untuk menghadapi tantangan seperti sentralisasi, upaya konservasi, di mana komunitas lokal dipindahkan untuk menciptakan area konservasi yang dilindungi (Peluso, 1993).

Hal yang sama juga dibuktikan oleh Lamers (2014) dalam penelitiannya yang membandingkan dua private-community partnership (PCP) yaitu The Koija Starbeds Ecolodge dan The Sanctuary at Ol Lentille di Kenya dalam mengelola wisata konservasi. PCP pada wisata konservasi merupakan pengaturan tata kelola yang penting untuk mencapai tujuan bersama konservasi alam, dan untuk meningkatkan mata pencaharian terutama di daerah di mana peran pemerintah kurang menonjol. PCP bersifat sangat politis dan dinamis, namun stabilitas dan perubahan di PCP konservasi dapat dijelaskan oleh kesesuaian internal dan eksternal dari berbagai dimensi pada pengaturan kebijakan partnerships. Kesesuaian internal dapat dilakukan dengan mempercayai satu sama lain walau kedua pihak memiliki logika dan wacana yang kontras (Meguro \& Inoue, 2011). Peranan metagovernance juga dibutuhkan untuk melindungi stabilitas sudut pandang kesesuaian internal dan eksternal (Lamers et al., 2014). Pengelolaan wisata konservasi diharapkan berlangsung efektif dan demokratis sehingga seluruh pelaku ekowisata baik dari pihak pemerintah maupun swasta dapat turut berperan.

Fokus lain yang dapat disorot pada penelitian pengelolaan ecolodge adalah branding. Cooperative branding adalah saat dua bisnis atau lebih bersama-sama menciptakan satu identitas baru terkait sebuah produk atau jasa, atau keduanya. Cooperative branding adalah sebuah perjanjian antar beberapa pihak dalam mengatur standar sebuah produk dan jasa, dan menciptakan koneksi antara merek dan konsumen (Park, 2013). Karena ecolodge belum memiliki sistem rating yang secara luas diterima untuk mengukur kualitas layanan, pemilik ecolodge menggunakan penilaian pribadi mereka dalam mengembangkan standar layanan di bisnis mereka (Ingribelli, 2012). Mic dan Eagles dalam penelitiannya menginvestigasi pengembangan strategi cooperative brand pada ecolodge skala menengah di Costa Rica (Mic \& Eagles, 2019). Di Costa Rica, ecolodge branding direpresentasikan oleh Certification for Sustainable Tourism Program (CST). CST digunakan sebagai kode etik untuk ekowisata dan wisata berbasis alam dan telah digunakan sebagai prototipe untuk mengembangkan berbagai program lingkungan (Honey, 2002). Meski CST adalah program sertifikasi ekowisata yang komprehensif dan dihormati, namun terdapat kritik dikarenakan CST yang awalnya ditujukan untuk pariwisata berkelanjutan berubah menjadi sertifikasi usaha berbagai kategori dan ukuran, termasuk hotel mewah dan persewaan mobil. Ecolodge tidak secara khusus dijabarkan dalam klasifikasi akomodasi pada CST (LePree, 2009).

Branding pada ecolodge dipandang sebagai peluang untuk berbagi sistem yang mencakup pemasaran, pelatihan, dan dukungan pengembangan (Honey, 2002). Empat keuntungan utama untuk gagasan branding yaitu: 1) jaminan standar kualitas, 2) dukungan operasional, 3) peningkatan pangsa pasar, dan 4) positioning yang lebih baik pada pasar. Menjaga kualitas layanan tanpa memiliki standar sebagai pedoman akan menjadi masalah terkait perbedaan layanan dan ketidakmampuan untuk bersaing dengan bisnis lain (Ingribelli, 2012). Partisipan ecolodge saat ini memiliki beberapa dimensi pendukung dalam pemasaran, pelatihan, dan biaya operasional yang kesulitan dalam meningkatkan performa ekonominya (Mic \& Eagles, 2019). Branding pada ecolodge dapat mengurangi permasalahan terkait kualitas layanan, dan meningkatkan kemampuan untuk bersaing dengan bisnis lain seperti akomodasi konvesional. Merek ecolodge yang dikenal dengan luas dapat memberi eksposur terhadap bisnis berkelanjutan sehingga dapat menjangkau pasar yang benar-benar berminat.

\section{Ecolodge in Locals Perspective: Ethical Issue and Capacity Building}

Ecolodge harus mengupayakan untuk bekerja bersama dengan masyarakat lokal (Wood, 2015). Penelitian ecolodge beberapa tahun terakhir tidak terlepas dari eksplorasi keterlibatan masyarakat lokal di sekitar lokasi ecolodge didirikan. Hunt dan Stronza dalam penelitiannya mengungkap persepsi lokal 
dalam membandingkan ekowisata yang ideal dan kenyataannya untuk berkontribusi pada perspektif tuan rumah lokal mengenai etika dalam pariwisata yaitu penduduk lokal di sekitar Morgan's Rock Hacienda and Ecolodge, Nicaragua (Hunt \& Stronza, 2011). Bagaimana masyarakat lokal terlibat dalam pengembangan pariwisata dan bagaimana keuntungan dan kerugian yang dirasakan masyarakat dalam pengembangan pariwisata. Upaya ecolodge mencapai keberlanjutan yang ideal dengan mengimplementasikan apa saja yang tercantum di program sertifikasi dapat mengabaikan masyarakat lokal dan memungkinkan adanya greenwashing (Hunt \& Stronza, 2011). Greenwashing adalah praktik palsu dalam mengklaim keberlanjutan (Honey, 2008). Greenwashing terjadi ketika sebuah organisasi memasarkan dirinya sebagai 'green', namun hanya sedikit mengimplementasikan prinsip dan praktiknya. Organisasi-organisasi tersebut berkomunikasi dan memiliki strategi pemasaran yang tidak jelas untuk memberi kesan yang salah dari destinasi ekowisata untuk meningkatkan pendapatan tanpa upaya tertentu dalam melestarikan lingkungan alam di sekitar. Greenwashing erat kaitannya dengan etika. Beberapa penelitian telah merekomendasikan untuk memperhatikan aspek etika pada pariwisata (Craig Wight \& John Lennon, 2007; D. A. Fennell, 2006).

Penelitian seputar etika diperlukan untuk mencari perbedaan antara ekowisata yang bertanggungjawab dengan praktik greenwashing. Hal ini penting bagi keberlanjutan pariwisata dan efektivitas program sertifikasi pariwisata berkelanjutan. Memperhatikan etika untuk menghindari greenwashing dapat dilakukan dengan cara sebagai berikut: (1) Melibatkan masyarakat lokal dalam memberikan informasi pada wisatawan untuk mempengaruhi pembelian saat berwisata; (2) Memikirkan konsep keberlanjutan yang ideal untuk jangka panjang; (3) Mengizinkan masyarakat lokal untuk memberi perspektif komparatif tentang hasil dari ekowisata dan bagaimana pengembangan pariwisata dapat menjadi lebih baik untuk mereka; (4) Mendistribusikan keuntungan pariwisata dengan komunitas lokal.

Beberapa prinsip dasar dalam pengelolaan ecolodge mencakup aspek community participation, environment conservation, ecological orientation, conservation dan nature education. Pelatihan dan pendidikan juga merupakan aspek fundamental untuk ecolodge. Community participation merupakan bagian dari sistem ecolodge yang mengupayakan keterlibatan masyarakat lokal dalam pengadaan barang, tenaga kerja, proses perencanaan pembangunan. Sebaliknya ecolodge berperan untuk memberi umpan balik yang positif bagi kesejahteraan dan peningkatan kualitas hidup masyarakat lokal. Community-based Tourism (CBT) dipercaya memiliki potensi dalam meningkatkan bukan hanya pemasukan dan pekerjaan masyarakat lokal, namun juga untuk mengembangkan ketrampilan, institusi, dan memberdayakan masyarakat lokal (Caroline Ashley and Elizabeth Garland, 1994). Tantangan untuk keterlibatan dan partisipasi komunitas adalah komunitas dihadapkan oleh kekurangan seperti kapasitas yang terbatas, pengetahuan pasar dalam mendesain produk, akses yang terbatas untuk informasi, ketrampilan, dan modal (Moscardo, 2008).

Dalam mengurangi tantangan yang dihadapi komunitas untuk berpartisipasi dalam inisiatif pengembangan pariwisata, konsep pengembangan kapasitas menjadi semakin penting karena pemerintah, donatur, dan agen implementasi berusaha untuk menyadari dampak yang lebih berkelanjutan dari dukungan pengembangan. Pemahaman mengenai hasil intervensi pengembangan kapasitas sangat penting karena kesuksesan CBT baik dalam konservasi dan pengembangannya bergantung pada keterlibatan komunitas (Cheers et al., 2005). Penelitian ecolodge yang fokus pada keterlibatan masyarakat lokal dapat mengaitkannya dengan konsep pengembangan kapasitas atau capacity building. Intervensi pengembangan kapasitas dapat dinilai menggunakan lima dimensi dari Learning Organization Model yaitu: sistem berpikir, penguasaan personal, model mental, visi bersama, dan pembelajaran tim (Senge, 2006).

Intervensi pengembangan kapasitas mencerminkan respon terhadap kebutuhan kritis untuk inisatif community-based conservation. Namun sebagian besar intervensi community-based memiliki hasil yang bervariasi untuk pertumbuhan inklusif (Imbaya et al., 2019). Intervensi pengembangan kapasitas dalam pengembangan communitybased conservation menawarkan peluang yang besar untuk pertumbuhan inklusif komunitas. Namun tetap berhubungan dengan kekuasaan politik dan aturan komunitas. Hasil dari 
intervensi pengembangan kapasitas di CBT juga dipengaruhi oleh lingkungan kontekstual di tempat CBT beroperasi seperti isu terkait politik, hubungan kekuasaan, pendanaan, dan budaya yang dianut. Pengembangan kapasitas untuk komunitas lokal sangat penting dalam mengimplementasikan dampak keberlanjutan dari bantuan pembangunan kepada komunitas.

\section{Ecolodge And Indigenous Tourism}

Dalam beberapa dekade terakhir terdapat upaya yang cukup besar untuk mendukung penduduk asli atau pribumi (indigenous) untuk memasuki industri pariwisata (HigginsDesbiolles et al., 2014). Dalam kriteria pengembangan ekowisata disebutkan fase perencanaan harus mengikuti dan menghormati kerjasama. Kerjasama yang dilakukan seringkan dengan masyarat lokal yang memiliki hak untuk berpartisipasi langsung dalam bisnis dan beroperasi dalam ecolodge di berbagai cara. Sebagai contoh, masyarakat lokal diharapkan menjadi penyedia bahan baku, mereka juga harus diperkerjakan dan bekerja di posisi yang tersedia, serta memberi pengetahuan pada wisatawan seputar budaya dan lingkungan alam mereka. Keterlibatan tersebut dapat membuahkan manfaat bagi masyarakat lokal secara ekonomi dan finansial, sama halnya dengan ecolodge yang akan lebih sukses dan sejahtera. Namun sejumlah perusahaan wisata Indigenous Australia yang didirikan dan sukses tergolong sedikit, serta penelitian yang mengangkat topik tersebut juga terbatas (Higgins-Desbiolles et al., 2014). Indigenous experience telah menjadi sebuah prioritas, namun sebagian besar dalam pengembangannya tejadi kekosongan informasi, yang kemungkinan terjadi karena tingkat kegagalan yang terlalu tinggi di antara perusahaan wisata (Ellis, 2003). Penelitian yang dilakukan Higgins-Desbiolles berkolaborasi dengan George Trevorrow pemilik The Coorong Wilderness Lodge (CWL) untuk mengungkap kesulitan yang dialami operator tur Indigenous Australia selama menjalani bisnis indigenous tourism. Ecolodge yang menjadi bagian dari indigenous tourism dapat menciptakan peluang ekonomi bagi penduduk asli. Meski begitu pengembangan indigenous tourism bukan hanya memiliki dampak eknomi, namun meliputi serangkaian masalah yang kompleks dan beragam termasuk tantangan dalam manfaat sosial, budaya, dan lingkungan. Pelaku bisnis indigenous tourism membutuhkan pemahaman dari pemerintah dan ahli dalam industri tersebut untuk bagaimana cara mensukseskan perusahaan tersebut.

Beberapa permasalahan yang dimiliki komunitas indigenous dan mempengaruhi perkembangan dan operasi strategi ekonomi daerah seperti pariwisata adalah isu pendidikan, pengangguran, pertumbuhan populasi remaja, kapasitas masyarakat lokal, dan berbagai isu sosial lainnya (Lemelin et al, 2012). Terdapat penelitian yang memeriksa indikator kesuksesan untuk bisnis indigenous secara general dan beberapa di antaranya lebih spesifik pada pariwisata (Heather, 2006; Hinch \& Butler, 2009; Ryan \& Aicken, 2005). Lemelin dalam penelitiannya mengembangkan indikator untuk indigenous tourism yang sukses dan bagaimana pengaplikasiannya, kemudian terdapat juga faktor-faktor yang digunakan untuk mengevaluasi kesuksesan perusahaan indigenous tourism yang bisa dilihat pada Tabel 1. Dengan mengadopsi kerangka berpikir tersebut dapat membuat penilaian yang lebih baik karena berdasarkan kenyataan serta benarbenar menumbuhkan pengembangan ekonomi jangka panjang dengan potensi pertumbuhan yang lebih kuat. Penting halnya bagi perencana, pembuat kebijakan, pemberi dana dan peneliti untuk membedakan antara indikator kesuksesan dan mengevaluasi kesuksesan. Indikator kesuksesan memberikan faktor-faktor untuk dipertimbangkan dalam perencanaan dan eksekusi perusahaan pariwisata, sedangkan faktor-faktor yang digunakan untuk mengevaluasi kesuksesan adalah cara menganalisis hasil positif atau negatif dari perusahaan. Faktor untuk mengevaluasi kesuksesan dapat mencakup hasil yang tidak dapat diukur, yang mungkin tidak mudah diukur secara kuantitatif, namun akan membantu pemahaman implikasi pengembangan indigenous tourism.

\section{Ecolodge Experiences Reported Online}

Ecolodge merupakan segmen ekowisata yang penting dan menyediakan bukan hanya akomodasi, namun juga pengalaman ekowisata karena wisatawan yang tinggal di ecolodge memiliki akses langsung ke sumber daya alam di sekeliling akomodasi (Lai \& Shafer, 2005). Berbeda dengan bentuk akomodasi lainnya, ecolodge menawarkan kesempatan bagi wisatawan untuk mendapat pengalaman yang bertanggung jawab dan konstruktif. Ecolodge memberikan pengalaman yang holistik dengan 
keadaan sosial, budaya, dan lingkungan alam di sekitar sekaligus menawarkan pembelajaran, pengetahuan, dan perspektif baru pada wisatawan.

Tabel 1

Kerangka Kerja Potensial Holistik untuk Analisis Keberhasilan Indigenous tourism

\begin{tabular}{|l|l|}
\hline Indikator Kesuksesan & Evaluasi Kesuksesan \\
\hline $\begin{array}{l}\text { EKONOMI } \\
\text { Sumber pendanaan } \\
\text { Infrastruktur }\end{array}$ & $\begin{array}{l}\text { Tahun didirikan } \\
\text { Mekerjaan }\end{array}$ \\
Jumlah operasi \\
Pendapatan
\end{tabular}

Sumber: Lemelin, Kostel, Youroukos (2015)

Dalam pariwisata, metode riset pemasaran yang paling sering digunakan untuk mempelajari pengalaman konsumen adalah survei dan kartu komentar tamu, namun metode tersebut memiliki tingkat respon yang rendah (Crotts et al., 2009). Lu dan Stepchenkva mengambil data penelitiannya dari usergenerated content (UGC) yang mudah diakses, kredibel, dan tersedia online untuk mempelajari pengalaman dan kepuasan konsumen yang tinggal di ecolodge. Review online untuk ecolodge di Costa Rica yang diunggah oleh wisatawan Amerika di TripAdvisor digunakan dalam analisis. Terdapat 26 atribut dari pengalaman ecolodge yang memberikan pandangan komprehensif tentang fitur ecolodge yang menonjol bagi wisatawan Amerika di Costa Rica. Atribut-atribut tersebut mempengaruhi kepuasan wisatawan saat tinggal di ecolodge dan terbagi menjadi empat kelompok yaitu: criticals, satisfiers, dissatisfiers, dan neutrals (Lu \& Stepchenkova, 2012). Klasifikasi atribut kepuasan wisatawan terhadap ecolodge bisa dilihat pada Tabel 2.

Pada bisnis pariwisata, kemampuan untuk mendemonstrasikan komitmen level tinggi dan keterlibatan dalam praktik keberlanjutan menjadi semakin penting dikarenakan konsumen yang sebelumnya belum menjadi wisatawan ramah lingkungan kini secara progresif menjadi lebih sadar akan isuisu lingkungan dan keberlanjutan. Namun dengan tingginya permintaan untuk produk ekowisata, tidak semua wisatawan memiliki motivasi pelestarian lingkungan. Wisatawan dapat terlibat di ekowisata baik produk dan aktivitasnya karena memiliki minat untuk menikmati lingkungan dan alam di mana aktivitas ekowisata berlangsung (Beaumont, 2011). Inkonsistensi dari pendorong permintaan ekowisata membutuhkan eksplorasi yang lebih jauh tentang refleksi konsumen ekowisata pasca pembelian. Penelitian terdahulu terkait keputusan pembelian wisatawan ekowisata cenderung fokus pada faktor-faktor perilaku yang mempengaruhi pengambilan keputusan pra-pembelian seperti nilai, sikap, kepercayaan dan niat (Braithwaite, 1997; Cheng et al., 2016.; Deng, 2007; Kerstetter et al., 2004; Rathnayake, 2016).

Saat konsumen ekowisata telah berpartisipasi dalam sebuah pengalaman ekowisata, atribut dari pengalaman mana yang dinilai tinggi atau lebih mempengaruhi kepuasan mereka? Seberapa menonjol aspek lingkungan dari pengalaman, jika dibandingkan dengan aspek produk, layanan atau estetika 
yang lebih umum? Hal ini dapat dijawab dengan evaluasi pasca konsumsi dari user-generated content (UGC) seperti travel review yang memberi peluang untuk menguraikan berbagai aspek penting yang dinilai konsumen ekowisata mempengaruhi pengalaman wisata mereka. Evaluasi pasca konsumsi melalui narasi online dapat menjabarkan gagasan unik dan holistik pada persepsi pengunjung sebagaimana yang mereka tulis setelah pengalaman dirasakan ditambah dengan pertimbangan dan refleksi (Holder, 2017).

Tabel 2

Klasifikasi Atribut Kepuasan

\begin{tabular}{|c|c|c|c|}
\hline Atribut & Klasifikasi & Atribut & Klasifikasi \\
\hline Suasana & Critical & $\begin{array}{l}\text { Proses } \\
\text { reservasi }\end{array}$ & Dissastifier \\
\hline $\begin{array}{l}\text { Ramah } \\
\text { lingkungan }\end{array}$ & Critical & $\begin{array}{l}\text { Aturan } \\
\text { manajemen }\end{array}$ & Dissastifier \\
\hline $\begin{array}{lr}\text { Tata letak } \\
\text { dan dekorasi } \\
\text { kamar dan } \\
\text { kamar } \\
\text { mandi }\end{array}$ & Critical & Atraksi alam & Dissastifier \\
\hline $\begin{array}{l}\text { Customer } \\
\text { service }\end{array}$ & Critical & Tamu lain & Sastifier \\
\hline $\begin{array}{l}\text { Layanan tur } \\
\text { dan } \\
\text { pemandu tur }\end{array}$ & Critical & $\begin{array}{l}\text { Aktivitas } \\
\text { berbasis } \\
\text { alam }\end{array}$ & Sastifier \\
\hline $\begin{array}{l}\text { Kulitas } \\
\text { makanan }\end{array}$ & Critical & $\begin{array}{l}\text { Aksesibilita } \\
\mathrm{s}\end{array}$ & Neutral \\
\hline $\begin{array}{l}\text { Harga } \\
\text { kamar }\end{array}$ & Critical & $\begin{array}{l}\text { Kedekatan } \\
\text { dengan kota }\end{array}$ & Neutral \\
\hline $\begin{array}{l}\text { Tanah dan } \\
\text { sekelilingny } \\
\text { a }\end{array}$ & Dissatisfier & $\begin{array}{l}\text { Kedekatan } \\
\text { dengan } \\
\text { atraksi }\end{array}$ & Neutral \\
\hline Kebisingan & Dissatisfier & $\begin{array}{l}\text { Layanan } \\
\text { tambahan }\end{array}$ & Neutral \\
\hline $\begin{array}{l}\text { Lodge } \\
\text { amenities }\end{array}$ & Dissatisfier & $\begin{array}{l}\text { Layanan } \\
\text { restoran }\end{array}$ & Neutral \\
\hline $\begin{array}{l}\text { Fasilitas } \\
\text { kamar dan } \\
\text { kamar } \\
\text { mandi }\end{array}$ & Dissastifier & $\begin{array}{l}\text { Harga } \\
\text { makanan } \\
\text { dan } \\
\text { minuman } \\
\end{array}$ & Neutral \\
\hline $\begin{array}{l}\text { Room } \\
\text { amenities }\end{array}$ & Dissastifier & $\begin{array}{l}\text { Harga-harga } \\
\text { lainnya }\end{array}$ & Neutral \\
\hline $\begin{array}{l}\text { Problem } \\
\text { serangga }\end{array}$ & Dissastifier & Cuaca & Neutral \\
\hline
\end{tabular}

Sumber: Lu \& Stepchenkova (2012)

Penelitian yang dilakukan oleh Ruhanen berbeda dengan penelitian terdahulu tentang ekowisata, tidak fokus pada motivasi dan niat konsumen, namun memeriksa laporan diri reflektif dari pengalaman wisatawan untuk menentukan keunggulan aspek eco dalam pengalaman dibandingkan atribut pengalaman pariwisata yang lebih umum. Terdapat tujuh tema utama yang merepresentasikan atribut yang paling sering diidentifikasi dari review produk ekowisata (Ruhanen, 2019), bisa dilihat pada Tabel 3. Permintaan produk ekowisata lebih didorong oleh ketertarikan pada pengalaman wisatawan dibanding minat spesifik pada pengalaman ekowisata yang berkelanjutan. Bagi banyak konsumen ekowisata, layanan dan pengalaman lebih penting atau berdampak lebih besar pada refleksi pasca pembelian dibanding pengalaman eco itu sendiri. Aspek lingkungan yang dinilai oleh konsumen ekowisata adalah yang terhubung dengan produk wisata seperti area sekeliling akomodasi. Oleh karena itu, sulit untuk membedakan apakah konsumen ekowisata memiliki kepedulian terhadap isu lingkungan dan keberlanjutan atau apakah aspek lingkungan dari kunjungan tersebut diasumsikan sebagai sifat asli dari produk ekowisata yang dibeli (Millar et al., 2012).

Tabel 3

Representasi Atribut yang Diidentifikasi dari Review Produk Ekowisata

\begin{tabular}{|c|c|}
\hline \multirow[b]{2}{*}{ Tema } & \\
\hline & Kode \\
\hline \multirow[t]{6}{*}{ Staff } & Keramahan staff \\
\hline & Pertolongan staff \\
\hline & Perilaku staff \\
\hline & Perasaan diterima \\
\hline & Layanan yang disediakan staff \\
\hline & $\begin{array}{l}\text { Deskripsi dari interaksi yang } \\
\text { dilakukan dengan staff }\end{array}$ \\
\hline \multirow[t]{5}{*}{ Fasilitas } & $\begin{array}{l}\text { Deskripsi fasilitas } \\
\text { amenities akomodasi }\end{array}$ \\
\hline & $\begin{array}{l}\text { Penilaian kualitas akomodasi } \\
\text { dan fasilitas/amenities }\end{array}$ \\
\hline & Deskripsi lokasi akomodasi \\
\hline & Akses \\
\hline & Kenyamanan \\
\hline \multirow[t]{5}{*}{ Alam } & Keindahan \\
\hline & Lansekap \\
\hline & Pemandangan (scenery) \\
\hline & Pemandangan (views) \\
\hline & $\begin{array}{l}\text { Interaksi dengan satwa liar } \\
\text { setempat }\end{array}$ \\
\hline \multirow[t]{2}{*}{ Makanan } & Pasokan makanan \\
\hline & $\begin{array}{l}\text { Fasilitas yang disediakan } \\
\text { untuk makan/memasak }\end{array}$ \\
\hline Pembelajaran & $\begin{array}{l}\text { Referensi pendidikan atau } \\
\text { pengalaman pembelajaran } \\
\text { yang ditemui saat menginap }\end{array}$ \\
\hline \multirow[t]{3}{*}{ Pengalaman } & Kemampuan untuk bersantai \\
\hline & Atmosfer akomodasi \\
\hline & Cuaca \\
\hline
\end{tabular}

Sumber: Ruhanen (2019)

Wisatawan yang mengunjungi lokasi ekowisata seringkali menilai lingkungan 
sebagai penentu utama yang berkontribusi pada kualitas pengalaman liburan mereka karena mereka ingin mengunjungi lingkungan alam yang menarik dan tidak mengalami kerusakan (Puhakka \& Siikamäki, 2012). Terdapat perbedaan yang ditunjukkan dari niat lingkungan wisatawan dan perilaku lingkungan selanjutnya, penelitian yang fokus pada refleksi pasca pembelian dapat membantu pemahaman dalam membedakan hal tersebut dari wisatawan. Penelitian berikut akan menunjukkan apakah permintaan produk dan pengalaman ekowisata berkelanjutan benarbenar tinggi, dan apakah permintaan tersebut hanya didorong oleh minat wisatawan terhadap pengalaman yang didapat saat berada di lingkungan alami, untuk kesenangan pribadi, pembelajaran, atau aktivitas fisik dan petualangan (Lu \& Stepchenkova, 2012).

\section{Arah dan Kontribusi Penelitian Ecolodge di Masa Mendatang}

Tinjauan literatur ini menyajikan hasil yang diperoleh dari penelitian terdahulu dengan topik ecolodge. Salah satu hal yang dieksplorasi dalam penelitian ecolodge adalah pengelolaannya. Pengelolaan meliputi kesesuaian ecolodge dengan label eco yang ada pada merek yang dapat diukur dengan mencocokkannya dengan berbagai panduan pelaksanaan ekowisata, seperti The International Ecolodge Guidelines. Penelitian yang mengeksplor pengelolaan ecolodge dapat dijadikan contoh atau acuan untuk pendirian ecolodge di area terpencil maupun area yang memiliki potensi wisata alam lainnya.

Pengelolaan ecolodge membutuhkan keterlibatan seluruh pihak baik internal dan eksternal, namun keterlibatan tersebut membutuhkan tata kelola yang baik agar seluruh stakeholders dapat memberikan perspektifnya untuk pengembangan ecolodge di masa depan. Penelitian yang memeriksa kesesuaian internal dan eksternal dari kemitraan atau kerjasama yang dijalin di ecolodge yang dikelola lebih dari satu pelaku dapat memberi pemahaman lebih untuk bagaimana tata kelola kerjasama di pariwisata yang baik. Salah satu bentuk kerjasama untuk pengelolaan ecolodge adalah cooperative branding. Cooperative branding yang efektif dapat menciptakan dan meningkatan keberlanjutan jangka panjang. Penelitian seputar aplikasi dan implementasi dari konsep cooperative branding kedepannya dapat lebih fokus untuk menekankan branding dan bisnis tanpa mengubah ide keberlanjutan dari ecolodge.

Persepsi masyarakat lokal dalam pengembangan ecolodge juga merupakan hal yang disoroti oleh penelitian-penelitian ecolodge. Penelitian etnografi komparatif pada berbagai konteks ekowisata perlu dilakukan untuk memperjelas hubungan yang kompleks antara wacana ilmiah dan fenomena greenwashing di ekowisata. Mayoritas penelitian ekowisata cenderung fokus pada dampak, sedangkan terdapat problem penipuan dan pengucilan, sehingga perlu dilakukan analisis performa etika dari persepsi masyarakat lokal. Bukan hanya berdasarkan pada sertifikasi, namun masyarakat lokal juga dapat menambah gagasan melalui sudut pandang mereka untuk mewujudkan pariwisata yang berkelanjutan, baik secara ekonomi, lingkungan, dan sosial.

Salah satu bentuk efektif dalam pengelolaan ekowisata adalah communitybased tourism (CBT). Pengembangan kapasitas pada komunitas yang mengelola CBT dibutuhkan untuk keberlanjutan produk ekowisata, salah satunya adalah ecolodge. Konsep pengembangan kapasitas pada komunitas yang terlibat di community-based tourism sangat penting. Pengembangan kapasitas memungkinkan komunitas tersebut mengorganisir, membuat keputusan dan mengambil tindakan yang memperkuat partisipasi mereka dalam pengelolaan ecolodge. Penelitian yang fokus pada modalitas dan komponen dari intervensi pengembangan kapasitas untuk komunitas harus tepat waktu dan relevan, karena penelitian-penelitian tersebut akan mengarahkan organisasi nonpemerintah (NGO) dan lembaga-lembaga lain yang terlibat. Penelitian tersebut juga akan berkontribusi pada komunitas dengan memberi input tentang cara yang terbaik dalam mengurus intervensi pengembangan kapasitas.

Ecolodge didirikan di daerah dengan potensi alam yang unggul, seringkali berada di kawasan lindung. Penduduk asli (indigenous) di sekitar kawasan lindung juga terkena dampak sosial-ekonomi dari didirikannya ecolodge di tanah leluhur mereka. Penelitian tentang indigenous tourism mayoritas fokus pada permintaan wisatawan, isu ceruk pariwisata budaya, dan pemasarannya. Masih sedikit penelitian yang menarik fokus pada bagaimana pemerintah mendukung pengembangan bisnis wisata indigenous dan bagaimana kaitannya 
dengan pemimpin bisnis wisata indigenous. Penelitian tersebut perlu dilakukan agar terdapat pemahaman lebih untuk mensukseskan pengembangan bisnis indigenous tourism. Penelitian tentang indigenous tourism yang dilakukan bersama penduduk asli memungkinkan untuk memberikan narasi yang lebih detail dalam memahami dinamika indigenous tourism. Meskipun terdapat peluang untuk terjadinya bias perspektif, namun penelitian tersebut tetap dapat berkontribusi dalam memberikan cerita pengembangan infrastruktur yang lebih seimbang. Dalam meneliti indigenous tourism diperlukan kerangka berpikir solid yang tidak hanya mempertimbangkan konteks sosial dan geografis, namun juga elemen yang tidak dapat diukur seperti kebanggaan komunitas. Hal ini seringkali diabaikan namun penting untuk strategi pariwisata lokal dan regional.

$$
\text { Ecolodge sebagai akomodasi }
$$

berkelanjutan perlu memberi perhatian khusus pada konsumennya untuk pengelolaan dan pengembangan yang tepat. Dalam meneliti kepuasan konsumen kedepannya dapat menggunakan wawancara kualitatif dan focus group discussions, agar peneliti dapat memastikan keaslian data. Penggunaan usergenerated content (UGC) dari review online sebagai data dapat menimbulkan pertanyaan dalam memvalidasi identitas konsumen apakah benar-benar wisatawan atau bukan. Penelitian tentang kepuasan konsumen ecolodge dapat dilakukan dengan menyusun daftar standardisasi atribut dan memvalidasinya menggunakan data online. Penelitian tipe ini dapat digunakan selain untuk mengevaluasi keluhan pelanggan, juga dapat digunakan untuk menilai kinerja ecolodge. Atribut dari kepuasan konsumen ecolodge dapat digunakan untuk menyortir prioritas dalam pengelolaan, dan ketika sumber daya terbatas maka ecolodge dapat lebih fokus untuk mengurangi ketidakpuasan di atribut tertentu dan memaksimalkan kepuasan di atribut lainnya, sehingga pengelolaan dapat berlangsung lebih efektif dan efisien

Penelitian ekowisata terdahulu cenderung fokus pada faktor-faktor perilaku yang mempengaruhi pilihan pra-pembelian. Dibutuhkan penelitian yang mengeksplor nilai dari aspek lingkungan yang dimiliki konsumen ekowisata ketika mereka sudah membeli dan mengonsumsi pengalaman ekowisata. Pemahaman terhadap nilai pengunjung atau hal yang menonjol dalam refleksi pasca pembelian dapat memudahkan pemasaran usaha dan produk untuk menargetkan alur pemasaran yang lebih baik dan memanfaatkan hal-hal yang dihargai oleh pengunjung. Kedepannya dapat dilakukan penelitian yang menganalisis niat pra-pembelian dihubungkan dengan ketertarikan wisatawan pada pengalaman ekowisata. Selain itu, penelitian kedepannya dapat memeriksa hal-hal yang penting bagi wisatawan, bukan hanya dari atribut keberlanjutan, melainkan dari persepsi pribadi wisatawan. Penelitian berikutnya juga dapat mengkombinasikan evaluasi pra dan dan pasca pembelian untuk membandingkan ekspektasi wisatawan sebelum membeli dan penilaian pasca pembelian produk ekowisata.

\section{METODE PENELITIAN}

Tulisan ini merupakan conceptual paper dengan tipe literature review. Literature review adalah evaluasi kritis dan mendalam dari penelitian-penelitian terdahulu (Kiteley \& Stogdon, 2016). Tulisan ini mereview artikelartikel dari tiga portal jurnal ilmiah, yaitu Wiley Online Library, Science Direct, dan Proquest. Pada portal jurnal ilmiah tersebut, penulis melakukan pencarian secara terminologi dengan kata kunci "ecolodge", dan "tourism". Penambahan kata kunci "tourism" dilakukan untuk menyaring artikel-artikel yang berasal dari bidang studi lain yang juga sering mengangkat topik ecolodge yaitu arsitektur, lingkungan, konservasi satwa, antropologi, dan geografi. Kemudian pencarian penulis saring lagi dengan membatasi tahun publikasi antara tahun 2009 hingga 2019, hal ini dilakukan penulis agar artikel yang direview masih relevan.

Pencarian tersebut pada masing-masing portal jurnal ilmiah menghasilkan sembilan artikel di Wiley Online Library, 13 artikel di Proquest, dan 34 artikel di Science Direct. Totalnya sebanyak 56 artikel. Dari sejumlah artikel tersebut, penulis menemukan beberapa artikel yang menggunakan bahasa selain Bahasa Inggris yang menjadi pengecualian. Kemudian penulis membaca abstrak dari masing-masing artikel dan memilih artikel yang merupakan penelitian empiris. Penulis kemudian menggolongkan artikel-artikel tersebut ke dalam dua kategori, yaitu artikel yang hanya sekilas menyebutkan kata "ecolodge" dan artikel yang menjadikan ecolodge sebagai objek penelitiannya. Artikel yang menjadikan 
ecolodge sebagai objek penelitian tersisa sejumlah sembilan artikel, masing-masing adalah satu artikel dari Wiley Online Library, satu artikel dari Proquest, dan tujuh artikel Science Direct. Sehingga total artikel yang direview pada tulisan ini adalah sejumlah sembilan artikel (lihat Tabel 4). Dalam mereview, penulis tidak hanya berhenti pada membaca literatur, namun juga merangkum, menganalisis, dan melakukan sintesis secara kritis dan mendalam dari artikel-artikel yang direview atau ditinjau.

Tabel 4

Penelitian Empiris yang Digunakan dalam Tinjauan Sistematis

\begin{tabular}{|c|c|c|c|}
\hline Judul & Tahun & Peneliti & Lokasi Penelitian \\
\hline $\begin{array}{l}\text { The Wenhai Ecolodge: A Case Study } \\
\text { of Culture and Environment in } \\
\text { Southwest China }\end{array}$ & 2010 & Sara Beth Keough & Cina \\
\hline $\begin{array}{l}\text { Missing the Forest for the Trees?: } \\
\text { Incongruous Local Perspectives on } \\
\text { Ecotourism in Nicaragua Converge } \\
\text { on Ethical Issues }\end{array}$ & 2011 & $\begin{array}{l}\text { Carter A. Hunt dan } \\
\text { Amanda L. Stronza }\end{array}$ & Nicaragua \\
\hline $\begin{array}{l}\text { Ecotourism experiences reported } \\
\text { online: Classification of satisfaction } \\
\text { attributes }\end{array}$ & 2012 & $\begin{array}{l}\text { Weilin Lu dan } \\
\text { Svetlana Stepchenkova }\end{array}$ & Costa Rica \\
\hline $\begin{array}{l}\text { Governing conservation tourism } \\
\text { partnerships in Kenya }\end{array}$ & 2014 & $\begin{array}{l}\text { Machiel Lamers, } \\
\text { Rene van der Duim, } \\
\text { Jakomijn van Wijk, } \\
\text { Rita Nthiga, } \\
\text { Ingrid J. Visseren-Hamakers }\end{array}$ & Kenya \\
\hline $\begin{array}{l}\text { The Coorong Wilderness Lodge: A } \\
\text { case study of planning failures in } \\
\text { Indigenous tourism }\end{array}$ & 2014 & $\begin{array}{l}\text { Freya Higgins-Desbiolles, } \\
\text { George Trevorrow, } \\
\text { Syd Sparrow }\end{array}$ & Australia \\
\hline $\begin{array}{l}\text { Tangible and intangible indicators of } \\
\text { successful aboriginal tourism } \\
\text { initiatives: A case study of two } \\
\text { successful aboriginal tourism lodges } \\
\text { in Northern Canada }\end{array}$ & 2015 & $\begin{array}{l}\text { Raynald Harvey Lemelin, } \\
\text { Rhonda Koster, } \\
\text { Nicholina Youroukos }\end{array}$ & Kanada \\
\hline $\begin{array}{l}\text { Cooperative branding for mid-range } \\
\text { ecolodges: Costa Rica case study }\end{array}$ & 2019 & $\begin{array}{l}\text { Monica Mic dan } \\
\text { Paul F.J. Eagles }\end{array}$ & Costa Rica \\
\hline $\begin{array}{l}\text { Capacity building for inclusive } \\
\text { growth in community-based tourism } \\
\text { initiatives in Kenya }\end{array}$ & 2019 & $\begin{array}{l}\text { Imbaya B. O., } \\
\text { Nthiga R.W., } \\
\text { Sitati N.W., } \\
\text { Lenaiyasa P. }\end{array}$ & Kenya \\
\hline $\begin{array}{l}\text { The prominence of eco in ecotourism } \\
\text { experiences: An analysis of post- } \\
\text { purchase online reviews }\end{array}$ & 2019 & Lisa Ruhanen & Australia \\
\hline
\end{tabular}

\section{KESIMPULAN DAN SARAN \\ Kesimpulan}

Literature review ini bertujuan untuk memaparkan hasil penelitian ecolodge yang sudah ada, sehingga dapat menyajikan hal yang sudah diketahui dan belum diketahui untuk memberikan arah penelitian kedepannya. Penggunaan systematic review pada penelitian pariwisata masih sangat terbatas (Weed, 2006). Nilai dari sebuah literature review bergantung pada apa yang telah dilakukan, apa yang ditemukan, kejelasan dalam melaporkan yang berdasar pada interpretasi penelitian yang asli (Hall et al., 2016). Literature review penelitian ecolodge ini mengindikasikan sejumlah isu-isu signifikan yang menjadi fokus pada penelitian. Hasil tinjauan menunjukkan penelitian ecolodge memiliki kontribusi yang berbeda tergantung pada subtopik atau isu apa yang diangkat. Hal yang dapat digarisbawahi dari hasil literature review ini adalah penelitian jangka panjang yang terintegrasi antara pengelola ecolodge dan pihak lain yang terlibat, seperti masyarakat lokal dan konsumen sangat perlu untuk dilakukan.

\section{Saran}

Berdasarkan simpulan di atas dapat diidentifikasi bahwa penelitian ecolodge di masa depan dapat menekankan pada kebutuhan 
untuk melibatkan seluruh stakeholders dalam mengembangkan ecolodge menjadi sarana akomodasi yang berkelanjutan. Perlu diadakan penelitian yang menghubungkan antara pengelola ecolodge, penduduk lokal dan konsumen, melihat bagaimana perubahan praktik pengelolaan ecolodge seiring waktu, atau melakukan penelitian pada lokasi dengan kondisi infrastruktur yang berbeda agar dapat mengevaluasi performa ecolodge di berbagai aspek.

\section{DAFTAR PUSTAKA}

Beaumont, N. (2011). Ecotourism: impacts, potentials and possibilities. Annals of Leisure Research, 14(4), 390-392. https://doi.org/10.1080/11745398.2011.6 39443

Blangy, S., \& Mehta, H. (2006). Ecotourism and ecological restoration. Journal for Nature Conservation, 14(3-4), 233-236. https://doi.org/10.1016/j.jnc.2006.05.009

Bohdanowicz, P. (2005). European hoteliers' environmental attitudes: Greening the business. Cornell Hotel and Restaurant Administration Quarterly, 46(2), 188204.

https://doi.org/10.1177/00108804042738 91

Braithwaite, V. (1997). A Social Values Segmentation of the Potential Ecotourism Market. Article in Journal of Sustainable Tourism.

https://doi.org/10.1080/09669589708667 274

Buckley, R. (2010). Conservation tourism. In Conservation Tourism.

Bulatović, D. S. D. (2017). Ecotourism and Ecolodge Accommodation. ILIRIA International Review, 7(2). https://doi.org/10.21113/iir.v7i2.331

Caroline Ashley and Elizabeth Garland. (1994). Number 4 October 1994 PROMOTING COMMUNITY-BASED TOURISM DEVELOPMENT Why, What and How? by Caroline Ashley and Elizabeth Garland. 4.

Cheers, B., Cock, G., Keele, L., Kruger, M., \& Trigg, H. (2005). Measuring community capacity: An electronic audit tool. http://www.academia.edu/download/7642 249/cheers_et_al.pdf
Cheng, A., Lu, C., \& Chiappa, G. Del. (2016). The Influence of Materialism on Ecotourism Attitudes and Behaviors Senior tourists View project Emotional segmentation View project. Journal of Travel Research, 1-14. https://doi.org/10.1177/00472875145410 05

Craig Wight, A., \& John Lennon, J. (2007). Selective interpretation and eclectic human heritage in Lithuania. Tourism Management, 28(2), 519-529. https://doi.org/10.1016/j.tourman.2006.03 .006

Crotts, J. C., Mason, P. R., \& Davis, B. (2009). Measuring guest satisfaction and competitive position in the hospitality and tourism industry: An application of stance-shift analysis to travel blog narratives. Journal of Travel Research, 48(2),

139-151. https://doi.org/10.1177/00472875083287 95

Deng, J. (2007). The New Environmental Paradigm and Nature-Based Tourism Motivation park, recreation and tourism View project Claude Worthington Benedum Foundation_Tucker County Tourism Planning View project. Article in Journal of Travel Research. https://doi.org/10.1177/00472875073083 31

Ellis, C. (2003). Participatory Environmental Research in Tourism: A Global View. Tourism Recreation Research, 28(3), 4555. https://doi.org/10.1080/02508281.2003.1 1081416

Elrouby, I. (2016). Ecolodging as an Answer for Sustainable Development and Successful Resource Management - The Case of North West Coast in Alexandria. 2016(8), 2839-2851.

Fennell, D. A. (2006). Evolution in tourism: The theory of reciprocal altruism and tourist-host interactions. Current Issues in Tourism, 9(2), 105-124. https://doi.org/10.1080/13683500608668 241

Fennell, D., \& Dowling, R. (2003). Ecotourism policy and planning. https://books.google.com/books?hl=en\&l 
$\mathrm{r}=\& \mathrm{id}=\mathrm{ywH} 2 \mathrm{jUwOCfkC} \&$ oi $=$ fnd $\& \mathrm{pg}=\mathrm{P}$ R9\&dq=Fennell,+D.+A.,+\%26+Dowling, + R.+K.+(Eds.).+(2003).+Ecotourism+pol icy+and+planning. + CABI.\&ots $=t C x z q g$ mEI-

$\&$ sig=nsKkFqGZv8iLzHTuOEhRKPIQE fw

Hall, C. M., Dayal, N., Majstorović, D., Mills, H., Paul-Andrews, L., Wallace, C., \& Truong, V. D. (2016). Accommodation consumers and providers' attitudes, behaviours and practices for sustainability: A systematic review. Sustainability (Switzerland), 8(7), 1-30. https://doi.org/10.3390/su8070625

Hawkins, D., tourism, M. K.-G., \& 1998, undefined. (n.d.). 11 Ecotourism opportunities for developing countries. Books.Google.Com. Retrieved October 1, 2019, from https://books.google.com/books?hl=en\&l $\mathrm{r}=\& \mathrm{id}=\mathrm{d}$ 9UrBgAAQBAJ\&oi=fnd \&pg=P A191\&dq=Hawkins, + D. + E., $+\% 26+$ Khan ,+M.+M.+(1998).+11+Ecotourism+oppor tunities+for+developing+countries.+Glob al+tourism,$+191 . \&$ ots $=$ dx9FXpNi8H\&si $\mathrm{g}=9 \mathrm{bO} 2 \mathrm{oP} 7 \mathrm{CQ}$ ahHiEDFHM5avkHvVek

Heather, Z. D. (2006). Indigenous ecotourism: Sustainable development and management. In Indigenous Ecotourism: Sustainable Development and Management.

https://books.google.co.id/books?hl=en\&l $\mathrm{r}=\& \mathrm{id}=$ noFNSuofi6IC\&oi=fnd\&pg=PR5 $\& \mathrm{dq}=$ Zeppel, + H.+(2006).+Indigenous+e cotourism:+Sustainable+development + an $\mathrm{d}+$ management $+($ Vol. +3$) .+$ Cabi.\&ots $=\mathrm{kj}$ $\mathrm{q} 8 \mathrm{nQmwEu} \&$ sig=wQRS8J-

cjx60Up9BQfLSrV2hwSg\&redir_esc $=y \#$ $\mathrm{v}=$ onepage $\& \mathrm{q}=\mathrm{Zeppel} \% 2 \mathrm{C} \mathrm{H}$

Higgins-Desbiolles, F., Trevorrow, G., \& Sparrow, S. (2014). The Coorong Wilderness Lodge: A case study of planning failures inIndigenous tourism. Tourism Management, 44, 46-57. https://doi.org/10.1016/j.tourman.2014.02 .003

Hinch, T., \& Butler, R. (2009). Indigenous tourism. Tourism Analysis, 14(1), 15-27. https://doi.org/10.3727/10835420978897 0117

Holder, A. (2017). Identifying the relative importance of culture in Indigenous tourism experiences: netnographic evidence from Australia. https://doi.org/10.1080/02508281.2017.1 316443

Honey, M. (2002). Ecotourism \& certification: Setting standards in practice. https://books.google.com/books?hl=en\&l $\mathrm{r}=\& \mathrm{id}=\mathrm{R} 0 \mathrm{bfqTkfkb} 4 \mathrm{C} \&$ oi=fnd\&pg=PR1 $1 \& \mathrm{dq}=$ Honey, + M. $+($ Ed. $)+(2002) .+$ Ecoto urism+\%26+certification:+Setting+stand ards+in+practice. + Island + Press. $\&$ ots $=\mathrm{OB}$ sv6noU1G\&sig=crq6GH5p_4EBBZHbQ5QmPg6AhA

Honey, M. (2008). Ecotourism and sustainable development: Who owns paradise? https://books.google.com/books?hl=en\&l $\mathrm{r}=\& \mathrm{id}=\mathrm{Jw}$ 2hy_2E5nwC\&oi=fnd\&pg=PR $5 \& \mathrm{dq}=$ Honey, + M.+(2008).+Ecotourism + and+sustainable+development:+Who+ow ns+paradise $\% 3 \mathrm{~F} .+$ Island + Press. \&ots $=8 \mathrm{q}$ nWmVbbw7\&sig=bBc_bWobfYwRHMgkkaUa8y5J3Q

Hunt, C., \& Stronza, A. (2011). Missing the forest for the trees?: Incongruous local perspectives on ecotourism in Nicaragua converge on ethical issues. Human Organization, 70(4), 376-386. https://doi.org/10.17730/humo.70.4.xj187 458416w1gr8

Imbaya, B. O., Nthiga, R. W., Sitati, N. W., \& Lenaiyasa, P. (2019). Capacity building for inclusive growth in community-based tourism initiatives in Kenya. Tourism Management Perspectives, 30(January), $11-18$. https://doi.org/10.1016/j.tmp.2019.01.003

Ingribelli, J. (2012). Perception of Importance and Performance of Certified Costa Rican Ecolodges.

Keough, S. B. (2010). The wenhai ecolodge: A case study of culture and environment in southwest China. Focus on Geography, 53(2), 65-71. https://doi.org/10.1111/j.19498535.2010.00009.x

Kerstetter, D. L., Hou, J. S., \& Lin, C. H. (2004). Profiling Taiwanese ecotourists using a behavioral approach. Tourism Management, 25(4), 491-498. https://doi.org/10.1016/S02615177(03)00119-5 
Kiper, T. (2013). Role of Ecotourism in Sustainable Development. Advances in Landscape Architecture. https://doi.org/10.5772/55749

Kiteley, R., \& Stogdon, C. (2016). What Is a Literature Review? In Literature Reviews in Social Work (pp. 5-22). https://doi.org/10.4135/9781473957756.n 2

Lai, P. H., \& Shafer, S. (2005). Marketing ecotourism through the internet: An evaluation of selected ecolodges in Latin America and the Caribbean. Journal of Ecotourism, 4(3), 143-160. https://doi.org/10.1080/JET.v4.i3.pg143

Lamers, M., van der Duim, R., van Wijk, J., Nthiga, R., \& Visseren-Hamakers, I. J. (2014). Governing conservation tourism partnerships in Kenya. Annals of Tourism Research, 48, 250-265. https://doi.org/10.1016/j.annals.2014.07.0 04

Lemelin, R. H., Koster, R., \& Youroukos, N. (2015). Tangible and intangible indicators of successful aboriginal tourism initiatives: A case study of two successful aboriginal tourism lodges in Northern Canada. Tourism Management, 47, 318328.

https://doi.org/10.1016/j.tourman.2014.10 .011

LePree, J. (2009). Certifying sustainability: The efficacy of Costa Rica's certification for sustainable tourism. Florida Atlantic Comparative Studies Journal, 11(20082009), 57-78.

Lu, W., \& Stepchenkova, S. (2012). Ecotourism experiences reported online: Classification of satisfaction attributes. Tourism Management, 33(3), 702-712. https://doi.org/10.1016/j.tourman.2011.08 .003

Meguro, T., \& Inoue, M. (2011). Conservation goals betrayed by the uses of wildlife benefits in community-based conservation: The case of Kimana sanctuary in Southern Kenya. Human Dimensions of Wildlife, 16(1), 30-44. https://doi.org/10.1080/10871209.2011.5 31516

Mehta, H. (2002). International Ecolodge
Guidelines. The International Ecotourism Society.

Mic, M., \& Eagles, P. F. J. (2019). Cooperative branding for mid-range ecolodges: Costa Rica case study. Journal of Outdoor Recreation and Tourism, 25(September 2017),

113-121. https://doi.org/10.1016/j.jort.2017.12.001

Millar, M., Mayer, K. J., \& Baloglu, S. (2012). Importance of Green Hotel Attributes to Business and Leisure Travelers. Journal of Hospitality Marketing and Management, 21(4), 395-413. https://doi.org/10.1080/19368623.2012.6 24294

Moscardo, G. (2008). Sustainable Tourism Innovation: Challenging Basic Assumptions. Tourism and Hospitality Research, 8(1), 4-13. https://doi.org/10.1057/thr.2008.7

Osland, G. E., \& Mackoy, R. (2004). Ecolodge performance goals and evaluations. Journal of Ecotourism, 3(2), 109-128. https://doi.org/10.1080/14724040408668 153

Park, D., international, R. N.-C. 3rd, \& 2013, undefined. (n.d.). Relationship between destination image and loyalty: developing cooperative branding for rural destinations. Media.Bizwebmedia.Net. Retrieved October 1, 2019, from http://media.bizwebmedia.net/sites/14652 7/upload/documents/20-destinationsbranding.pdf

Peluso, N. L. (1993). Coercing conservation?. The politics of state resource control. Global Environmental Change, 3(2), 199$217 . \quad$ https://doi.org/10.1016/09593780(93)90006-7

Puhakka, R., \& Siikamäki, P. (2012). Nature tourists response to ecolabels in Oulanka PAN Park, Finland. Journal of Ecotourism, 11(1), 56-73. https://doi.org/10.1080/14724049.2011.6 47917

Rathnayake, R. M. W. (2016). Willingness to pay for a novel visitor experience: ecotourism planning at Kawdulla National Park in Sri Lanka. Tourism Planning and Development, 13(1), 37-51. https://doi.org/10.1080/21568316.2015.1 


\section{5}

Ruhanen, L. (2019). The prominence of eco in ecotourism experiences: An analysis of post-purchase online reviews. Journal of Hospitality and Tourism Management, 39(April), 110-116. https://doi.org/10.1016/j.jhtm.2019.03.00 6

Ryan, C., \& Aicken, M. (2005). Indigenous tourism: The commodification and management of culture. https://books.google.com/books?hl=en\&l $\mathrm{r}=\& \mathrm{id}=\mathrm{CobH}$ XXIID0C\&oi=fnd\&pg=PP $1 \& \mathrm{dq}=$ Ryan,$+\mathrm{C} .,+\% 26+$ Aicken, + M.+(Ed s.).+(2005). +Indigenous+tourism: + The $+\mathrm{c}$ ommodification+and + management + of $+\mathrm{c}$ ulture.+Elsevier.\&ots $=u F 0$ Unwyq3 \&sig=B2o0GdYgyiXmKKqNkOkJO8te5M

Senge, P. (2006). The fifth discipline: The art and practice of the learning organization.

Sirakaya-Turk, E., Baloglu, S., \& Mercado, H. U. (2014). The Efficacy of Sustainability Values in Predicting Travelers' Choices for Sustainable Hospitality Businesses. Cornell Hospitality Quarterly, 55(1), 115-126.

https://doi.org/10.1177/19389655134998 22

Weed, M. (2006). Sports tourism research 2000-2004: A systematic review of knowledge and a meta-evaluation of methods. Journal of Sport and Tourism, $11(1)$, 5-30. https://doi.org/10.1080/14775080600985 150

Wood, M. E. (2015). Ecotourism: Priciples, Practices, and Policies for Sustainability. In International Encyclopedia of the Social \& Behavioral Sciences: Second Edition. https://doi.org/10.1016/B978-008-097086-8.91071-7 